\title{
The Effectiveness of YEARS and Wells Diagnostic Criteria in the Emergency Department with Suspected Pulmonary Thromboembolism
}

\author{
Acil Serviste Pulmoner Tromboemboli Şüphesinde YEARS ve Wells Tanı Kriterlerinin Etkinliği
}

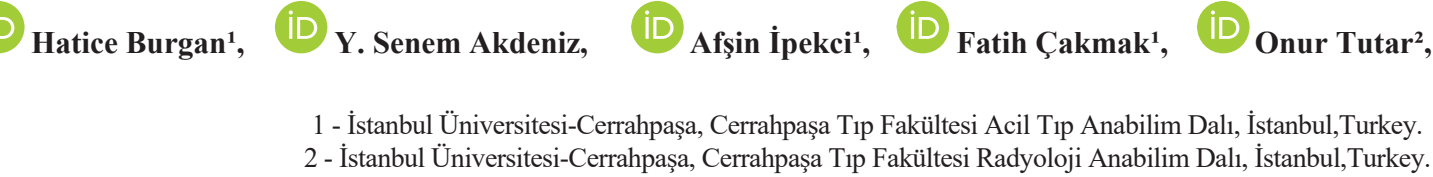

\begin{abstract}
Objective: Pre-diagnosis of pulmonary thromboembolism is non-specific and computed tomographic pulmonary angiography is a common method for diagnosis. However, unnecessary use increases the diagnosis of subsegmental emboli, exposure of patients to extra radiation and, can cause contrast nephropathy. In this study, we aimed to investi-gate and compare the effectiveness of YEARS and well diagnostic criteria in suspected pulmonary thromboembolism patients at the emergency department.

Material and Method: This study was run in suspected thromboembolism patients who were evaluated through Wells and YEARS diagnostic criteria and, to whom computed tomographic pulmonary angiography scans were recommended by at least one of these algorithms, in Emergency Department. The YEARS and Wells scores, D-dimer values and, angiography results of patients were analyzed.

Results: $55.74 \%$ of patients were males and $44.26 \%$ were females. The mean age of patients was $59.77 \pm 16.07$. The most common comorbidity is a malignancy with a rate of $44.26 \%$. A significant difference was not detected on D-dimer values between patients with and without a pulmonary embolus. A significant difference was not detected in D-dimer values in patients whose diagnosis was likely to be pulmonary embolism or unlikely on Wells criteria. The sensitivity and specificity of the YEARS criteria were found to be $93.75 \%$ and $24.44 \%$, respectively. Positive predictive values and negative predictive values were found to be $30.61 \%$ and 91.66 , respectively. The sensitivity and specificity values of Wells criteria were found to be $62.50 \%$ and $80 \%$, respectively. Positive predictive value and negative predictive value were found to be $52.63 \%$ and $85.71 \%$, respectively.

Conclusion: According to the results of our study, the most specific algorithm in pulmonary embolism diagnosis is Wells criteria and, the most sensitive one is the YEARS criteria. For ruling out the disease both algorithms are effective; YEARS is a little more powerful, whereas both are weeks for diagnosis.
\end{abstract}

\section{ÖZET}

Amaç: Pulmoner tromboemboli öntanısı non spesifiktir ve Toraks Bilgisayarl Tomografi Anjiografisi slk kullanılan bir tanı yöntemidir. Ancak gereksiz kullanımı subsegmental emboli tanılarını arttırmakta, hastaları fazladan radyasyona maruz bırakmakta ve kontrast nefropatisine yol açabilmektedir. Bu çalş̧mada acil serviste pulmoner emboliden şüphelendiğimiz hastalar üzerinde YEARS ve Wells tanı kriterlerinin etkinliğini inceleyip karşılaştırmayı amaçladık.

Gereç ve Yöntem: Bu çalışma acil serviste pulmoner emboliden şüphelenilen hastaların YEARS ve Wells tanı kriterlerine göre skorlaması yapılarak, en az bir algoritmaya göre Toraks Bilgisayarl Tomografi Anjiografi çekilmesi önerilen hastalar üzerinde prospektif olarak yapıldı. Bu hastaların YEARS ve Wells tanı kriterlerine göre puanları, D-dimer değerleri ve anjiyografi sonuçları değerlendirildi.

Bulgular: Hastaların \%55.74'ü erkek, \%44.26’sı kadınlardan oluşmaktadır. Hastaların yaş ortalaması 59.77 \pm 16.07 ylldır. En sık komorbidite \%44.26 ile malignitelerdir. Emboli saptanan ve saptanmayan grupların D-dimer değerleri arasında anlamlı fark saptanmamıştır. Wells algoritmasına göre pulmoner tromboemboli olasılığ olan ve olmayan hastaların D-dimer değerleri arasında anlamlı fark saptanmamıştır. YEARS algoritmasının sensitivi-tesi $\% 93.75$, spesifitesi $\% 24.44$ olarak tespit edilmiștir. Pozitif prediktif değer \%30.61, negatif prediktif değer \%91.66 olarak hesaplanmıştır. Wells algoritmasının duyarlılı̆̆ \%62.50, özgüllüğ̈̈ \%80 olarak hesaplanmıştır. Pozitif prediktif değer \%52.63, negatif prediktif değer \%85.71 olarak tespit edilmiştir.

Sonuç: Çalışmamızın sonucuna göre acil serviste pulmoner tromboemboli tanısı koymada en özgül Wells algoritmasl, en duyarlı YEARS algoritmasıdır. Hastalı̆̆ dışlamada ise YEARS biraz daha güçlü olmakla beraber her iki algoritma da etkilidir ancak tanı koydurmakta etkileri zayıftır.
Keywords:

Pulmonary embolism,

YEARS,

Wells

Anahtar Kelimeler:

Pulmoner emboli,

YEARS,

Wells

Correspondence: Yonca Senem Akdeniz. İstanbul Üniversitesi-Cerrahpaşa, Cerrahpaşa Tıp Fakültesi Acil Tıp Anabilim Dalı, İstanbul,Turkey. E-mail: ysa@istanbul.edu.tr

Cite this article as: Burgan H, Akdeniz YS, Ipekci A, Cakmak F, Tutar O, Ikizceli I. The effectiveness of YEARS and wells diagnostic criteria in the emergency department with suspected pulmonary thromboembolism. Phnx Med J. 2021;3(1):35-39. 


\section{GíRIŞ}

Sistemik dolaşımdan trombüs veya multipl trombüslerin pulmoner damarlara migrasyonuyla oluşan durum pulmoner tromboembolizm (PTE) olarak adlandirılır (1). PTE, mortalitesi ve morbiditesi yüksek, tekrarlayabilen, önlenebilir ve acil bir hastalıktır (2).

Yaşla birlikte insidansı artar ve 80 yaş üzerinde yaklaşık 10 kat artış gösterir ve hastanedeki ölümlerin \%10 unun sebebini oluşturur (3).

Klinik tablo embolinin büyüklüğüne, sayısına, bulunduğu yere, hastanın yaşına ve kardiyopulmoner hastalık varlığına göre değişiklik gösterir (4). Hastaların çoğunda nefes darlığ1, göğüs ağrısı mevcuttur (5). Ancak kendine özgü semptom ve bulguları olmadığı için gözden kaçabilir (2). PTE tanısında eskiden altın standart olan pulmoner anjiografinin yerini invaziv olmayan ve benzer görüntü kalitesine sahip Toraks Bilgisayarlı Tomografi Anjiografi (TBTA) almıştır (6). Tanı koymayı hızlandırmak, desteklemek veya tanıyı dışlayabilmek için Wells, Geneva ve YEARS gibi klinik olasılık algoritmaları oluşturulmuştur $(7,8)$. Güncel çalışmalar klinik olasılık değerlendirmeleri ile beraber yaşa göre Ddimer değerinin kullanımını önermektedir $(9,10)$.

Her gün acil gibi hekimleri göğüs ağrısı ve nefes darlığ semptomları olan hastalarla karşılaşmaktadır. Bazı hastalarda tanı koymak güç olabilmektedir. Bu çalışmada YEARS ve Wells kriterlerini acil serviste PTE şüphesi ile Toraks Bilgisayarlı Tomografi Anjiografisi (TBTA) çektiğimiz hastalar üzerinde değerlendirdik ve etkinliklerini karşılaştırdık.

\section{GEREÇ VE YÖNTEM}

Bu ileriye dönük gözlemsel çalışma, İstanbul Üniversitesi Cerrahpaşa Tıp Fakültesi Acil Tıp Anabilim Dalı Acil Servisinde 31887016-804.01-181195 say1lı etik kurul izni alınmasını takiben 01/03/2018 ile 01/09/2018 tarihleri arasinda yapildi.

Acil servise herhangi bir semptomla başvurup PTE şüphesi olan tüm hastalar YEARS ve Wells kriterlerine göre değerlendirildi.

Tablo 1: Hastalarda mevcut olan ek hastalıklar

\begin{tabular}{lcc} 
Ek hastalık & $\begin{array}{c}\text { Hasta sayısı } \\
(\mathbf{n})\end{array}$ & $\begin{array}{c}\text { Hasta yüzdesi } \\
(\%)\end{array}$ \\
\hline Malignite & 27 & $\% 44.26$ \\
Kardiovaskuler hastalık & 22 & $\% 36.07$ \\
Pulmoner hastalık & 9 & $\% 14.75$ \\
Endokrinolojik & 9 & $\% 14.75$ \\
Nörolojik & 5 & $\% 8.20$ \\
Romatolojik & 4 & $\% 6.56$ \\
Morbid obezite & 3 & $\% 4.92$ \\
Faktör 5 Leiden sendromu & 2 & $\% 3.28$ \\
Nefrolojik & 1 & $\% 1.64$ \\
Hiçbir ek hastalık yok & 5 & $\% 8.20$ \\
\hline
\end{tabular}

Bunlardan en az birine göre TBTA çekilmesi önerilen hastalar çalışmaya alındı.

Acil tıp uzmanının klinik değerlendirmesi sonucu pulmoner tromboemboli öntanısı düşünülmeyen, YEARS veya Wells kriterlerine göre düşük olasılıklı, TBTA çekilmemiş, 18 yaş altı ve çalışmaya katılmak istemeyen hastalar çalışmadan çıkartıldı.

Hastaların acil servise başvurularında hasta ve hasta yakınları tarafindan belirtilen komorbid hastalıkları ve demografik bilgileri ile kan basıncı, nabız, vücut sıcaklığı, solunum sayıs1, D-dimer düzeyi, derin ven trombozu (DVT) bulgularının varlığı, daha önce geçirilmiş DVT, PTE varlığı, son 1 ay içerisinde geçirilmiş cerrahi operasyon varlığı, 3 günden fazla immobilizasyon varlığı, hemotizi şikâyetinin varlığı, YEARS, Wells puanları ve TBTA sonuçları kaydedilip değerlendirildi. Hastalardan mevcut durumlar için yapılan tetkikler dişında ek tetkik istenmedi. İstatistik analizi için IBM SPSS Statistic for Microsoft 20.0 (SPSS Inc, Chicago USA) programı kullanıldı. Verileri normal dağılımı uymadığı değerlendirmek için Kolmogorov-Simirnov testi kullanıldı. Çalışma verileri değerlendirilirken tanımlayıcı istatiksel metodlar (ortalama, medyan, frekans, oran, minimum, maksimum) kullanıldı. İki grup ortalamasının karşılaştırılmasında Student's-t testi kullanildı.

\section{BULGULAR}

Çalışmaya alınan 61 hastanın 34'ü (\%55.74) erkek, 27'si (\%44.26) kadındı. Kadınların yaşları 28 ile 91 arasında değişmekte olup, ortalaması $60.68 \pm 14.76$ yıldır. Erkeklerin yaşları 18 ile 84 yaşları arasında değişmekte olup, ortalaması $58.67 \pm 17.80$ yıldır. Tüm hastaların yaş ortalaması ise $59.77 \pm 16.07$ saptanmıştır.

Hastaların çoğunda birden fazla ek hastalık vardı, bunlar tablo 1' de ayrıntılı olarak verilmiştir.

Hastaların 16 (\%26.22)'sında PTE saptanmıştır, bu hastaların risk faktörleri tablo 2'de verilmiştir. Emboli saptadığımız 16 hastamızın 2'sinde hiçbir risk faktörü saptanmadı. Hastaların bir kısmında birden fazla risk faktörü birlikte bulunmaktayd.

Tablo 2: PTE saptanan hastaların $(n=16)$ risk faktörleri

\begin{tabular}{|c|c|c|}
\hline PTE için risk faktörleri & $\begin{array}{c}\text { Hasta sayısı } \\
\text { (n) }\end{array}$ & $\begin{array}{c}\text { Hasta yüzdesi } \\
(\%)\end{array}$ \\
\hline 65 yaş üstü olmak & 7 & $\% 11.47$ \\
\hline Malignite & 7 & $\% 11.47$ \\
\hline $\begin{array}{l}\text { Geçirilmiş cerrahi veya } \\
\text { immobilizasyon }\end{array}$ & 3 & $\% 4.92$ \\
\hline Geçirilmiş ${ }^{1} \mathrm{MI}$ & 3 & $\% 4.92$ \\
\hline $\begin{array}{l}\text { Geçirilmiş }{ }^{2} \text { DVT veya } \\
{ }^{3} \text { PTE öyküsü }\end{array}$ & 2 & $\% 3.28$ \\
\hline Morbid obezite & 2 & $\% 3.28$ \\
\hline Mevcut ${ }^{2}$ DVT & 2 & $\% 3.28$ \\
\hline Geçirilmiş ${ }^{4} \mathrm{SVO}$ & 1 & $\% 1.64$ \\
\hline Faktör 5 leiden sendromu & 1 & $\% 1.64$ \\
\hline Hiçbir faktörü yok. & 2 & $\% 3.28$ \\
\hline
\end{tabular}

${ }^{1}$ MI:: Miyokard İnfarktüsü, ${ }^{2}$ DVT: Derin Ven Trombozu, ${ }^{3}$ PTE: Pulmoner Tromboemboli ${ }^{4}$ SVO: Serebrovasküler Olay 
Tablo 3: Hastaların bulundurdukları primer malignite türüne göre dağılımı

\begin{tabular}{lcc} 
Primer malignite & $\begin{array}{c}\text { Hasta } \\
\text { sayısı } \\
(\mathbf{n})\end{array}$ & $\begin{array}{c}\text { Hasta } \\
\text { yüzdesi } \\
(\%)\end{array}$ \\
\hline Akciğer kanseri & 11 & 18.03 \\
Meme kanseri & 3 & 4.92 \\
Hodgkin lenfoma & 2 & 3.28 \\
Mide kanseri & 2 & 3.28 \\
Kolon kanseri & 2 & 3.28 \\
Over kanseri & 2 & 3.28 \\
Kronik lenfositik lenfoma & 1 & 1.64 \\
Diffüz büyük B hücreli lenfoma & 1 & 1.64 \\
Mezotelyoma & 1 & 1.64 \\
Beyin tümörü & 1 & 1.64 \\
Yumuşak doku sarkomu & 1 & 1.64 \\
\hline
\end{tabular}

Hastaların 27'sinde malignite saptanmıştır. Hastaların bulundurdukları malignite türüne göre dağılımı tablo 3 'te verilmiştir.

Hastaların YEARS algoritmasına göre puanları hesaplanıp sonuçları incelenmiştir. 27 hastanın (\%44.26) YEARS algoritmasına göre 0 puan aldığı, 34 hastanın (\%55.74 ) ise 1 veya daha büyük puan aldığı görülmüştür. YEARS puanını hesapladığımız hastaları D-dimer değerleri ile birlikte değerlendirdiğimizde, D-dimer sınır değerini, YEARS puanı $=0$ olan hastalar için $1 \mathrm{ng} / \mathrm{ml}$ $\geq$ YEARS puanı 1 olan hastalar için $0.5 \mathrm{ng} / \mathrm{ml}$ olarak kabul edilmiştir.

YEARS algoritmasına göre TBTA çekilmesi önerilen 49 hastanın 15 'inde emboli saptanmıştır; 34'ünde emboli saptanmamıştır (Tablo 4).

YEARS algoritmasına göre TBTA çekilmesi önerilmeyen
12 hastanın 1' inde emboli saptanmış olup, 11' inde emboli saptanmamıştır. Çalışmamıza göre YEARS algoritmasının sensitivitesi \% 93.75, spesifitesi \%24.44 olarak tespit edilmiştir. Pozitif prediktif değer \% 30.61, negatif prediktif değer $\% 91.66$ olarak hesaplanmıştır. Hastaların Wells algoritmasına göre puanları, 3 basamaklı ve 2 basamaklı olarak değerlendirilip ayrı ayrı oranları hesaplanmıştır.3 basamaklı değerlendirmeye göre hastaların 9 'u (\%14.75) yüksek klinik olasılıklı, 32 'si (\%52.46) orta klinik olasılıklı, 20 'si (\%32.79) düşük klinik olasılıklı olarak değerlendirildi (Tablo 5). Wells algoritmasında 3 basamaklı değerlendirmeye göre 61 hastadan 20 hastada (\%32.79) TBTA çekilmesine gerek kalmadan PTE tanısı dışlanabilmektedir. Wells algoritmasına göre 2 basamaklı değerlendirme yapıldığında, 42 hasta PTE olası değil ( Wells puanı $\leq 4$ ), 19 hasta PTE olası (Wells puanı $>4$ ) olarak sınıflandırılmıştır (Tablo 6).

Çalışmamıza göre Wells algoritmasının duyarlılığı $\% 62.50$, özgüllüğü \%80 olarak hesaplanmıştır. Pozitif prediktif değer $\% 52.63$, negatif prediktif değer $\% 85.71$ olarak tespit edilmiştir.

TBTA'da emboli saptanan hastaların Wells algoritmasından aldıkları puanların ortalaması 5.65 \pm 1.71 iken, emboli saptanmayan hastaların aldıkları puanların ortalaması $2.62 \pm 2.23$ olarak hesaplanmış olup istatiksel olarak anlamlı bulundu. TBTA'da emboli saptanan hastaların $(\mathrm{n}=16), \mathrm{D}$-dimer ortalamaları 7.06 \pm 9.89 iken, emboli saptanmayan hastaların D-dimer ortalamaları $3.12 \pm 5.26$ idi ve istatiksel olarak anlamlı fark tespit edilmedi.

Wells kriterlerine göre PTE olası grubun $(n=19)$ Ddimer ortalamas1 5.39 \pm 5.71 , PTE olası olmayan grubun $(\mathrm{n}=42)$ D-dimer ortalaması $3.59 \pm 7.39$ idi. İstatiksel olarak anlamlı fark tespit edilmedi.

Tablo 4: YEARS kriterlerine göre emboli saptanan ve saptanmayan hastaların dağılımı

\begin{tabular}{lccc} 
& Emboli saptanan & Emboli saptanmayan & Toplam \\
\hline${ }^{1}$ TBTA önerilen & 15 & 34 & 49 \\
${ }^{1}$ TBTA önerilmeyen & 1 & 11 & 12 \\
\hline Toplam & 16 & 45 & 61 \\
\hline
\end{tabular}

${ }^{1}$ TBTA: Toraks Bilgisayarlı Tomografi Anjiografi

Tablo 5: Hastaların Wells algoritmasına göre 3 basamaklı dağılımı

\begin{tabular}{lccc} 
Wells skoruna göre sınıflaması & Emboli saptanan & Emboli saptanmayan & Toplam hasta sayısı \\
\hline Yüksek klinik olasılıklı & 5 & 4 & 9 \\
Orta klinik olasılıklı & 11 & 21 & 32 \\
Düşük klinik olasılıklı & 0 & 20 & 20 \\
\hline
\end{tabular}

Tablo 6: Hastaların Wells algoritmasına göre 2 basamaklı dağılımı

\begin{tabular}{lccc} 
Wells skoruna göre & Emboli saptanan & Emboli saptanmayan & Toplam hasta sayısı \\
Sinıflaması & & & 9 \\
\hline${ }^{1}$ PTE olası & 10 & 36 & 19 \\
${ }^{1}$ PTE olası değil & 6 & 45 & 42 \\
\hline Toplam & 16 & 61 \\
\hline
\end{tabular}

${ }^{1}$ PTE: Pulmoner Tromboemboli 


\section{TARTISMA}

PTE, mortalitesi ve morbiditesi yüksek, tekrarlayabilen ve acil bir hastalıktır. Kendine özgü şikâyet ve bulgusu olmamakla birlikte klinik belirtiler ve eşlik eden komorbid hastalıklar nedeniyle maskelenebildiğinden tanıs1 güç olabilmektedir. Pulmoner tromboemboli olabilecek yönetiminin hızlı ve doğru bir şekilde yapılması acil hekimlerinin yükümlülükleri arasındadır. Kabrhel $\mathrm{C}$ ve arkadaşlarının acil serviste pulmoner emboli düşünülen hastalar üzerinde YEARS kriterlerini inceledikleri bir çalışmada, çalışmaya alınan 1789 hastanın 1134'ü (\%63) kadın, 655'i (\%37) erkeklerden oluşmaktadır (11).

Doğan ve arkadaşlarının PTE olgularını değerlendirdikleri retrospektif bir çalışmada, hastaların 58'i (\%46.8) kadın, 66's1 (\%53.2) erkeklerden oluşmaktadır (12). Bizim çalışmamızda hastalardan 34'ü (\%55.74) erkek, 27'si (\%44.26) kadın hastalardan oluşmaktadır ve sonuçlar ülkemizde yapılan çalışmalarla benzer bulunmuştur.

Yine Kabrhel ve arkadaşlarının yaptığı çalışmada hastaların yaş ortalaması $48 \pm 16$ yıl, Cesur ve arkadaşlarının yaptığı çalışmada yaş ortalaması $67 \pm 15$, Doğan ve arkadaşlarının çalışmasında yaş ortalaması 61.6 \pm 16.9 saptanmıştır (11-13). Bizim çalışmamızda benzer şekilde tüm hastaların yaş ortalaması $59.77 \pm 16.07$ iken, kadınların yaş ortalaması 60.68 \pm 14.76 , erkeklerin yaş ortalaması ise $58.67 \pm 17.80$ bulunmuştur.

Uyanık ve arkadaşlarının acil serviste PTE tanısı almış hastaların sosyodemografik olarak incelendiği çalışmasında en fazla görülen ek hastalıklar kardiyovaskuler hastalıklar, pulmoner hastalıklar ve ardından malignite olarak tespit edilmiştir (14). Doğan ve arkadaşlarının yaptığı çalışmada ise en sık malignite, ardından kardiyovaskuler hastalıklar tespit edilmiştir (12). Bizim çalışmamızda da en sık görülen ek hastalıklar malignite, ardından kardiyovaskuler hastalıklar saptanmıştır.

Miniati ve arkadaşlarının yaptıkları çalışmada PTE hastalarında risk faktörleri değerlendirilmiş ve immobilizasyon, malignite ve alt ekstremite kırıkları anlamlı olarak bulunmuştur (15). Kıral ve arkadaşları üzerinde çalıştıkları 27 hastanın \%37' sinde ileri yaş, $\% 18$ ' inde cerrahi girişim ve \%18.5 inde kalp hastalığ 1 saptamışlar (16). Çakmak ve Karadal'ın yaptıkları çalışmalarda ise en sık geçirilmiş DVT, alt ekstremite fraktürü ve cerrahi girişim saptamışlardır $(17,18)$. Yılmaz ve arkadaşlarının yaptığı çalışmada, en sık geçirilmiş cerrahi veya immobilizasyon, geçirilmiş DVT veya PTE ve kanser saptanmış (19). Bizim çalışmamızda da benzer şekilde $\% 43.75$ ileri yaş, $\%$ 43.75 malignite, \%18.75 geçirilmiş cerrahi veya immobilizasyon, \%18.75 geçirilmiş Mİ, \%12.5'inde geçirilmiş DVT veya PTE öyküsü tespit edilmiştir. Doğan ve arkadaşlarının yaptığı çalışmada, malignitesi olan hastalarda en fazla gastrointestinal sistem malignitesi (\%33.3) ve ardından akciğer malignitesi (\%28.6) saptanmıştır (12).
Bizim çalışmamızda 61 hastadan 27'sinde malignite mevcuttur ve de en fazla akciğer (\%18.03) ve meme kanseri (\%4.92) saptanmıştır.

Doğan ve arkadaşlarının yaptığı çalışmada, hastaların Wells skorlamasından aldıkları puanların ortalaması $2.74 \pm 1.08$ saptanmış olup, hastalar Wells skoruna göre 3 basamaklı yönteme göre (düşük, orta, yüksek) sınıflandırılmıştır (12). PTE tanisinda Wells skoru istatiksel olarak anlamlı bulunmuştur (12). Bizim çalışmamızda ise, TBTA emboli saptanan hastaların Wells algoritmasından aldıkları puanların ortalaması $5.65 \pm 1.71$ iken, emboli saptanmayan hasta-ların aldıkları puanların ortalaması $2.62 \pm 2.23$ olarak hesaplanmış olup, istatiksel olarak anlamlı bulunmuştur.

Van Belle ve arkadaşlarının yapmış olduğu çalışmada, 3306 hastanın 1057'sinde (\%32) Wells algoritması 2 basamaklı değerlendirmeye göre zayıf olasılık ve normal D-dimer değerleri saptanmış ve bu hastaların 3 aylık takiplerinde 5 hastada (\%0.5) PTE gelişmiş (20). Bizim çalışmamızda ise, Wells kriterlerine göre PTE olası grubun $(n=19)$ D-dimer ortalamas1 5.39 \pm 5.71 , PTE olas1 olmayan grubun $(n=42) d-$ dimer ortalaması $3.59 \pm 7.39$ idi ve anlamlı fark tespit edilmedi. Tick ve arkadaşlarının, yüksek d-dimer düzeyinin PTE tanısında yararını belirlemek amacıyla yaptıkları çalışmada d-dimer düzeyinin $2000 \mathrm{ng} / \mathrm{ml}$ üzerinde olan, düşük klinik olasılıklı hastaların \%36'sında PTE saptanmıştır (21). D-dimer düzeyleri $1000 \mathrm{ng} / \mathrm{ml}$ üzerine çıktığında, klinik olasılık skorlamalarından bağımsız olarak PTE sıklığının arttığını saptamışlardır (21). Bizim çalışmamızda ise emboli saptanan hastaların $(n=16)$, Ddimer ortalamaları 7.06 \pm 9.89 iken, emboli saptanmayan hastaların D- dimer ortalamaları $3.12 \pm 5.26$ idi ve anlamlı fark tespit edilmedi. Bunun sebebinin hastalarımızın Ddimer seviyesini yükselten komorbid hastalıklarının bulunmasından kaynaklanabileceğini düşünmekteyiz.

Van Der Hulle ve arkadaşlarının, akut PTE şüphesi olan hastalarda YEARS algoritmasının etkinliğini araştırdıkları ve Wells algoritması ile kıyasladıkları çalışmada, hiçbir YEARS kriteri bulunmayan 1743 hastanın 55 inde (\% 3.2) PTE saptanmış, bir veya daha fazla YEARS kriteri bulunan 1722 hastanın 401'i PTE tanısı almıştır (8). Hastalardan 6' S1 exitus olmuş ve ölüm sebebi olarak PTE dışlanamamıştır. Hastaların 3 aylık takiplerinde 18'inde PTE saptanmıştır. Çalışmanın sonucuna göre, hastalar üzerinde YEARS algoritması kullanıldığında TBTA \%14 azalma saptanmıştır. Wells algoritması kullanıldığında ise, TBTA gereksiniminde azalma \%8.7 saptanmıştır (8). Kabrhel ve arkadaşlarının acil serviste pulmoner emboli düşünülen hastalar üzerinde YEARS kriterlerini değerlendirdikleri bir çalışmada, 1789 hastanın 1204'ünde YEARS algoritmasına göre TBTA çekilmesi önerilmemiş ve bu hastaların 6'sında PTE saptanmış (11).

YEARS algoritması standart D-dimer eşiği ile birlikte kullanıldığında duyarlılığı \%97.6, D-dimerin yaşa bağlı cut-off değeri ile birlikte kullanıldığında ise duyarlılığı \%92.9 saptanmıştır (11). Negatif prediktif değer birçok çalışmada \%100'e yakın saptanmıştır (11). Bizim çalışmamızda da YEARS algoritmasının duyarlılığ $\%$ 93.75, özgüllügüü \%24.44, pozitif prediktif değeri \%30.61, negatif prediktif değeri ise \%91.66 saptanmıştır. 
Wells algoritmasının duyarlılığı \%62.50, özgüllüğü $\% 80$, pozitif prediktif değeri $\% 52.63$, negatif prediktif değeri \%85.71 olarak saptanmıştır. TBTA çekilen ve 78 (\%9.8)'inde PE saptanan 794 hasta ile yapılan retrospektif bir çalışmada YEARS algoritması $(\%$ 97.44) Wells'e göre daha duyarlı bulunmuştur (\% 74.36) ancak özgüllüğü daha düşüktür (\%13.97'e karş1 \%33.94) (22).

Ayrıca YEARS algoritmasının negatif prediktif değeri daha güçlü saptanmıştır (\%98'e karş1 \%92.4) ve her iki algoritmanın pozitif prediktif değeri zayıf (\%10.9) olarak bulunmuştur (22).

Sonuç olarak çalışmamıza göre acil serviste pulmoner tromboemboli tanısı koymada en özgül Wells algoritması ancak en duyarlı YEARS algoritmasıdır. Hastalığı dışlamada ise YEARS algoritması biraz daha güçlü olmakla beraber her iki algoritma da etkilidir ancak tanı koydurmakta etkileri zayıftır.

Çıkar Çatışması: Yazarlar çıkar çatışması olmadığını beyan etti.

\section{KAYNAKLAR}

1. Wendelboe AM, Raskob GE. Global burden of thrombosis: epidemiologic aspects. Circ Res 2016;118:1340-1347.

2. İpekci A. Pulmoner Emboli 2019. Phnx Med J. 2019; 1(1): 51-63.

3. Arseven O, Ekim N, Müsellim B, Oğuzülgen İK, Okumuş NG, Öngen ve ark. Pulmoner Tromboembolism Tanı ve Tedavi Uzlaşı Raporu. Türk Toraks Derneği, 2015.

4. Pollack CV, Schreiber D, Goldhaber SZ, Slattery D, Fanikos J, O'neil BJ, et al. Clinical characteristics, management, and outcomes of patients diagnosed with acute pulmonary embolism in the emergency department: initial report of EMPEROR (Multicenter Emergency Medicine Pulmonary Embolism in the Real World Registry). J Am Coll Cardiol 2011;57(6):700-706.

5. Stein PD, Terrin ML, Hales CA, Palevsky HI, Saltzman HA, Thompson BT, et al. Clinical, laboratory, roentgenographic, and electrocardiographic findings in patients with acute pulmonary embolism and no pre-existing cardiac or pulmonary disease. Chest 1991;100:598. Carrier

6. M, Righini M, Wells PS, Perrier A, Anderson DR, Rodger MA, et al. Subsegmental pulmonary embolism diagnosed by computed tomography: incidence and clinical implications. A systematic review and meta-analysis of the management outcome studies. J Thromb Haemost. 2010;8:1716-1722.

7. Yılmaz S, Topçu F, Selimoğlu Şen H, Abakay Ö, Yılmaz Z. Pulmoner emboli tanısında Wells klinik skorlaması ile yüksek D-dimer seviyesinin kombinasyonu. Journal Clinical and Experimental Investigations 2014;5(4):557-562.

8. van der Hulle T, Cheung WY, Kooij S, Beenen LFM, van Bemmel T, van Es J, et al. Simplified diagnostic management of suspected pulmonary embolism (the YEARS study): a prospective, multicentre, cohort study. Lancet. 2017;390(10091):289-297.

9. Konstantinides SV, Meyer G, Becattini C, Bueno H, Geersing GJ, Harjola VP, et al. 2019 Guidelines for the diagnosis and management of acute pulmonary embolism developed in collaboration with the European Respiratory Society (ERS). European Heart Journal 2019;00:1-61.

10. Righini M, Van Es J, Den Exter PL, Roy PM, Verschuren F, Ghuysenet A ,et al. Age-Adjusted D-Dimer cutoff levels to rule out pulmonary embolism The ADJUST-PE Study. JAMA. 2014;311(11):1117-1124.

11. Kabrhel C. Outcomes of high pretest probability patients undergoing d-dimer testing for pulmonary embolism: a pilot study. J Emerg Med. 2008;35:373-377.

12. Doğan C, Cömert SŞ, Çağlayan B, Mutlu Ş, Fidan A, Kıral N. Pulmoner trombo-emboli olgularımızın retrospektif değerlendirilmesi. İzmir Göğüs Hastalıkları Dergisi. 2016;1:15-21.

13. Cesur MT, Solmazgül E, Kardeşoğlu E, Ardıç N, Özmen N, Pekkafalı Z, ve ark. Pulmoner tromboemboli ve derin ven trombozu tanısında Ddimer testinin önemi. Nobel Med 2005; 1(2): 24-27.

14. Uyanık E, Yılmaz A, Eliçabuk H, Beydilli H, Dağı B,Avcil M. Acil serviste pulmoner emboli tanısı alan hastaların sosyodemografik-klinik özellikleri ve mortalite üzerine etkisi, Gaziosmanpaşa Üniversitesi Tıp Fakültesi Dergisi 2014;6(1):18-26.

15. Miniati M, Prediletto R, Formichi B, Marini C, Di Ricco G, Tonelli L, et al. Accuracy of clinical assessment in the diagnosis of pulmonary embolism. Am J Respir Crit Care Med 1999;159:864-871.

16. Kıral N, Salepçi B, Özdoğan S, Tevetlioğlu İ, Çağlayan B. Klinik olarak yüksek olasılıklı pulmoner emboli olgularımızın retrospektif analizi. Solunum Hastalıkları 2002;13:172-176.

17. Çakmak F, Isık C, Gündoğdu C. 1987-1999 yılları arasında Atatürk göğüs hastalıkları ve göğüs cerrahisi merkezinde akciğer embolisi tanısı konan hastaların retrospektif incelenmesi. Solunum Hastalıkları 1992;3:53-62.

18. Karadal F, Çetinkaya E, Yıldız P, Soysal F,Tekin A, Yılmaz V. Klinik olarak yüksek olasılıklı pulmoner emboli olgularında tanı. Solunum Hastalıkları 2000; 11:140-143.

19. Yılmaz S, Topçu F, Selimoğlu Şen H, Abakay Ö,Yılmaz Z. Pulmoner emboli tanısında Wells klinik skorlaması ile yüksek D-dimer seviyesinin kombinasyonu. Journal Clinical and Experimental Investigations. 2014;5(4):557-562.

20. Van Belle A, Buller HR, Huisman MV, Huisman PM, Kaasjager K, Kamphuisen PW, et al. Effectiveness of managing suspected pulmonary embolism using an algorithm combining clinical probability, d-dimer testing, and computed tomografhy. JAMA 2006;295:172-179.

21. Tick LW, Nijkeuter M, Kramer MHH, Hovens MMC, Büller HR, Leebeek FWG, et al. High D-dimer levels increase the likelihood of pulmonary embolism.J Intern Med 2008;264(2): 195-200.

22. Abdelaal Ahmed Mahmoud M Alkhatip A, Donnelly M, Snyman L, Conroy P, Hamza MK, Murphy I, et al.. YEARS Algorithm Versus Wells' Score: Predictive Accuracies in Pulmonary Embolism Based on the Gold Standard CT Pulmonary Angiography. Critical Care Medicine. 2020;48(5):704-708. 